\title{
Anatomical Studies of Wild Rice Accession for Evaluation of Resistance against Brown Plant Hopper
}

\author{
Rupesh Kumar Gajbhiye ${ }^{1}$, Abhinav Kumar ${ }^{2 *}$, Niyati pandey ${ }^{1}$ and Sanjay Sharma ${ }^{2}$ \\ ${ }^{1}$ Department of Entomology, College of Agriculture, Indira Gandhi Krishi Vishwavidyalaya, \\ Raipur, Chhattisgarh- 492012, India \\ ${ }^{2}$ Department of Entomology and Agricultural Zoology Institute of Agricultural Sciences, \\ Banaras Hindu University, Varanasi-221005, Uttar Pradesh, India \\ *Corresponding author
}

\section{A B S T R A C T}

Keywords

Brown plant hopper, Nilaparvata lugens, Oryza nivara, Resistance, Wild rice accessions

Article Info

Accepted:

25 April 2017

Available Online: 10 May 2017
Present investigation includes anatomical study of wild rice accessions at internodes position were carried out to understand the relationship between plant anatomy and resistance against Brown plant hopper. This study includes thickness of epidermis and distance between epidermis and vascular bundle and the corresponding evaluation of accessions through seed box technique. Maximum thickness of epidermis was observed in PTB $33(15.89 \mu \mathrm{m})$ followed by $O$. nivara D: $13(15.67 \mu \mathrm{m})$ and $O$. nivara VS: $83(14.05 \mu \mathrm{m})$. Maximum distance was observed in PTB 33 followed by $O$. nivara VS: 54 and $O$. nivara VSR: 54. Minimum distance was observed in TN1, followed by $O$. nivara MS: 7 and $O$. nivara VSR: 76. Minimum average plant damage score by BPH through standard seed box technique tested against BPH was observed in Twenty two rice accessions were categorized as highly resistant (HR).

\section{Introduction}

Rice is one of the important cereal crops of the world and forms the staple food for more than 50 per cent of population. Even though, there are many constraints in rice production, insects' pests remain a constant problem in all the rice growing regions (Manikandan Narayanasamy et al., 2014). Brown planthopper (BPH), Nilaparvata lugens (Stal) (Hemiptera: Delphacidae) is a typical piercing sucking insect pest of rice (Oryza sativa L.; Poaceae), which feeds on phloem sap and thus affects the growth of rice and results in "hopper burn" in rice fields (Park et al., 2008). In addition to direct damage, BPH also transmits viruses, such as the ragged stunt virus and grassy stunt virus, and associated diseases to rice plants (Jena et al., 2006). Attempts to control brown planthopper with chemical pesticides have given rise to many problems, including elimination of natural predators, environmental pollution, resurgence and outbreak (Balakrishna and 
Satyanarayana, 2013). It is considered viable to search the available genotypes for sources of resistance against BPH for use in breeding programme. In 1966, International Rice Research Institute, Philippines started work on varietal resistance for BPH. Extensive damage by BPH in India was first observed in Kerala during 1973. Subsequently reports were received from Andhra Pradesh, Bihar, Haryana, Orissa, Punjab, Tamil Nadu, and Uttar Pradesh (Kalode, 1974; Kulshrestha et al., 1974). Glass house screening is the primary method for identify of resistance donors further these isolated genotypes should be used for field screening then after identify the responsible gene for resistance. In this way, an attempt has been made in this study to examine the mass screening, probing marks and honeydew excretion for identification of new source of resistance against BPH. Moreover in the present WTO era where a lot of stress is given on quality parameters, the search for alternate methods of control becomes important (Tetarwal et al., 2014). Thus, the present studies were conducted to identify the new sources of resistance against brown plant hopper in rice.

\section{Materials and Methods}

Experiment on screening of rice genotypes against brown plant hopper, Nilaparvata lugens (Stal.) for identification of resistance donor was conducted in 2014-15, at the Glass house, Department of Entomology, Indira Gandhi Krishi Vishwavidyalaya, Raipur, Chhattisgarh. The experimental material consisted of ninety four genotypes along with TN- 1and PTB-33 as susceptible and resistant check, respectively Rearing and maintenance of BPH Brown plant hoppers initially collected from field were maintained throughout the year in the air cooled glasshouses at $30 \pm 5^{\circ} \mathrm{C}$ on forty day old $\mathrm{TN}-1$ seedlings in clay plots. The pots were placed inside rearing cages of $75 \times 75 \times 75$ cubic $\mathrm{cm}$ which consist with of an iron frame with glass panels and small window on front side and fine wire mesh on top and other sides.Adultinsects 3 to 4 pair (male and Female) per hill were placed inside rearing cages for egg laying. After 2-3 days, the females started egg lying inside the leaf sheath of paddy plant. Later on, when adults emerged they were transferred to another pot for egg laying. For transferring the adults, an aspirator is used which works on the suction of the air principle. Nymphs emerged out within5 to6 days from the eggs and reached second instar; they were collected and used to infest the test materials. Screening of rice genotypes was carried out by standard seed box screen testing method (Kalode et al., 1979). Mass screening tests were employed under controlled glasshouse conditions. The test and check material were pre germinated in Petri dishes $(10 \mathrm{~cm}$ diameter) and these geminated seeds were transferred to wooden boxes of the size $60 \times 40 \times 10 \mathrm{~cm}$ containing well mixed homogeneous and sterilized soil. Each seed box contained 24test lines with 20 seedlings of each including resistant check (Ptb-33) in two middle rows and susceptible check (TN-1) four border and 2 middle rows. After sowing the tray were placed on cemented platform with7.5 $\mathrm{cm}$ water for maintaining the moisture level. When the seedling become 7 to 10 day old age first and second instar nymph were uniformly released on the seedlings, so that each seedling must be get infested with least 8 to 10 nymphs. The observations were recorded710daysafterreleasinginsectswhenthe insect killed more than 90 percent of $\mathrm{TN}-1$ seedlings. The reactions were recorded on a 0-9 scale suggested by Heinrichs (1986).

Anatomical study of wild rice accessions at internodes positions were carried out to understand the relationship between plant anatomy and resistance for insect pest. This study includes distance between vascular 
bundle and epidermis at the inter-node positions and thickness of epidermis at the inter-node positions. All 53 wild rice genotypes were used for this anatomical study. The plant sample was collected at tillering stage (30-45 days after transplanting). For anatomical investigation hand sectioning method was followed. First, a levelling cut was made for the purpose of forming a right angle with the axis of the stem to ensure that the sections made were cross sections. After each cutting, the cut section that collected on the blade were transferred to a drop of water on a slide and covered with a cover slip by lowering it at an angle onto the drop of water containing the sections. The sections were mounted in the $50 \%$ glycerine and were examined under trinocular microscope. Anatomical study was carried out to study the distance between the epidermis to phloem located in vascular system of rice stem. This observation has been taken from the inter-nodal position to study the variations among different wild rice accessions. Also the thickness of epidermis was studied at the intermodal positions and the number of vascular bundle was counted. The aim of this study was to further explore the interactions between BPH insects feeding and rice plants in an attempt to elucidate the mechanisms involved in rice resistance to the $\mathrm{BPH}$. The mouthparts of $\mathrm{BPH}$, like other phloem feeding insects, consist of a stylet bundle which forms the piercing and sucking organ (Sogawa, 1982, Seo et al., 2009).

\section{Results and Discussion}

As per the standard evaluation of wild rice accessions tested against brown plant hopper Twenty two rice accessions Oryza latifolia, MS:21, VS:39, VS:48, VS:62, VSR:6, VSR 14, VSR:33, VSR:54, VSR:74, VS:54, VS:83, VS:89, VSR:11, VSR:13, VSR:47, D:3, D:28, D:29, D:30, D:32, PTB 33 were categorized as highly resistant (HR), seven accessions
Oryza officinalis MS:32 VS:40D:13 MS:50 VSR:35 D:11 categorized as resistant (R), three accessions VS:52 VSR:58 VSR:70 were categorized as moderate resistant, six accessions MS:19, VSR:76, D:40, D:31, D:37, D:5 were categorized as susceptible and fourteen accessions namely as MS:3, MS:36, VS:74, VS:98, VSR:16, D:34, MS:6, MS:7, MS:17, MS:34, VSR:26, VSR:53, VSR:56 D:1 and TN1were categorized as highly susceptible. The distance between outer layer and inner layer of epidermis i.e. thickness of epidermis varied from $3.65 \mu \mathrm{m}$ to $15.67 \mu \mathrm{m}$ in different wild rice accessions. Maximum thickness was observed in PTB $33(15.89 \mu \mathrm{m})$ followed by Oryza nivara D: $13(15.67 \mu \mathrm{m})$ and Oryza nivara VS: $83 \quad(14.05 \mu \mathrm{m})$. Minimum distance was observed in TN1 $(3.65 \mu \mathrm{m})$, followed by Oryza nivara MS: 7 $(3.67 \mu \mathrm{m})$ and Oryza nivara D: $37(3.72 \mu \mathrm{m})$. The present anatomical studies i.e. distance between epidermis to vascular bundle, thickness of epidermis and number of vascular bundle reveals that some of the wild rice accessions were found to be promising against brown planthopper. The promising wild rice accessions were Oryza officinalis, Oryza latifolia, MS: 21, D: 3, D: 30, D: 11, VS: 48 and VS: 83.These accessions showed maximum distance between epidermis to vascular bundle, maximum thickness of epidermis. Santhalakshmi et al., (2010) reported the genotype Ptb 33 as highly resistant to Indian biotype, while the variety Swarna was found susceptible to BPH. Likewise Velusamy et al., (1995) conducted study on three wild rice species viz., Oryza officinalis, Oryza punctata and Oryza latifolia to determine their mechanisms of resistance to Nilaparvata lugens. In a seed box screening test wild rice species had maintained their high level of resistance through the 48 hours exposure to N. lugens and significantly more individuals settled on susceptible TN 1 followed by cultivated resistant varieties. Nilaparvata lugens caged 
on resistant wild rice had showed slow nymphal development, reduced longevity, low fecundity and low egg hatchability as compared to $N$. lugens on cultivated resistant varieties. Also the study is in accordance with the Pham Thi Mui and Bui Ba Bongwork (1999) they showed the wild rice species $(O$. rufipogon, $O$. officinalis, $O$. nivara) possessed a high frequency of resistant accessions (68.2\% at scale 1-3) and almost all the traditional varieties in the Mekong Delta were susceptible to BPH. Bhogadhi et al., (2015) also work on screened Rice Genotypes for Resistance to $\mathrm{BPH}$. They screened 20 rice genotypes in field by standard evaluation system (IRRI, 1992). Further these genotypes were screened by standard seed box screening technique (SSST), honey dew test and nymphal survival test in the greenhouse in order to confirm the resistance and susceptibility. The results of field screening and SSST showed low BPH damage score (3.0) in BM71, ACC5098, ACC2398, MTU1001, Rathuheenathi Low honeydew excretion and low nymphal survival rate was observed in BM71, ACC5098 and
Rathuheenathi reflecting non-preference feeding behaviour and antibiosis mechanism of resistance, respectively. Madurangi et al., (2010) evaluated the nature of BPH resistance in seventeen O. nivara (WRAC 01, 02, 04, 07, 11, 12, 14, 19, 21, 22, 24, 25, 35, 41, 46, 62, and 9864) accessions through standard seed box screening test. According to the results WRAC 04, 41, 25 and PTB 33 recorded as resistant (score 0-3), WRAC 46, 35, 24, 22, 21, 14, 7, 2,1, 9864 and Bg 379/2 as resistant to moderately resistant (score 3.14.0), WRAC 11,12 and $\mathrm{Bg} 300$ as moderately resistant (score 4.1-5.0), WRAC 19 and 62 as moderately resistant to moderately susceptible (score 5.1-6.0), while no checked accessions were recorded as susceptible to the $\mathrm{BPH}$ indicating potential of using Oryza nivara as a source of BPH resistance. Bhagat (2014) conducted study on the anatomical variation of twenty $\mathrm{BPH}$ resistant donors of rice for intermodal section of stem. It is concluded that maximum distance between vascular bundle to epidermis was measured for PTB 33 followed by RP 2068-18-3-5 and Rathu Heenati (AC 11730).

Table.1 List of tested wild rice accessions

\begin{tabular}{|c|c|c|c|c|c|c|c|c|c|c|c|}
\hline $\begin{array}{l}\text { S. } \\
\text { No }\end{array}$ & $\begin{array}{l}\text { Accessions } \\
\text { No. }\end{array}$ & $\begin{array}{l}\text { S. } \\
\text { No }\end{array}$ & $\begin{array}{c}\text { Accessio } \\
\text { ns No. }\end{array}$ & $\begin{array}{c}\text { S. } \\
\text { No }\end{array}$ & $\begin{array}{c}\text { Accessio } \\
\text { ns No. }\end{array}$ & $\begin{array}{l}\text { S. } \\
\text { No }\end{array}$ & $\begin{array}{l}\text { Accessi } \\
\text { ons No. }\end{array}$ & $\begin{array}{l}\text { S. } \\
\text { No }\end{array}$ & $\begin{array}{c}\text { Accession } \\
\text { s No. }\end{array}$ & S. No & $\begin{array}{c}\text { Acces } \\
\text { sions } \\
\text { No. }\end{array}$ \\
\hline 1 & O.officinalis & 11 & VS:52 & 21 & VSR:74 & 31 & MS:17 & 41 & VSR:35 & 51 & D:30 \\
\hline 2 & O.latifolia & 12 & VS:62 & 22 & VSR:76 & 32 & MS:34 & 42 & VSR:47 & 52 & $\mathrm{D}: 11$ \\
\hline 3 & MS:3 & 13 & VS:74 & 23 & D:40 & 33 & MS:50 & 43 & VSR:53 & 53 & $\mathrm{D}: 32$ \\
\hline 4 & MS:19 & 14 & VS:98 & 24 & D:24 & 34 & VS:54 & 44 & VSR:56 & 54 & TN1 \\
\hline 5 & MS:21 & 15 & VSR:6 & 25 & $\mathrm{D}: 31$ & 35 & VS:83 & 45 & VSR:70 & 55 & $\begin{array}{l}\text { PTB } \\
33\end{array}$ \\
\hline 6 & MS:32 & 16 & VSR:14 & 26 & D:13 & 36 & VS:89 & 46 & D:1 & & \\
\hline 7 & MS:36 & 17 & VSR:16 & 27 & D:34 & 37 & VSR:11 & 47 & D:3 & & \\
\hline 8 & VS:39 & 18 & VSR:33 & 28 & D:37 & 38 & VSR:13 & 48 & D:5 & & \\
\hline 9 & VS:40 & 19 & VSR:54 & 29 & MS:6 & 39 & VSR:26 & 49 & $\mathrm{D}: 28$ & & \\
\hline 10 & VS:48 & 20 & VSR:58 & 30 & MS:7 & 40 & VSR:30 & 50 & D:29 & & \\
\hline
\end{tabular}


Table.2 Standards for rating damage by brown plant hopper (revised by irri-irtp, pathak and khush 1977)

\begin{tabular}{|l|l|l|}
\hline \multicolumn{1}{|c|}{ Grade } & \multicolumn{1}{|c|}{ Symptom } & Category \\
\hline 0 & No visible damage & HR \\
\hline 1 & Very slight damage & R \\
\hline 3 & 1 and 2 leaf partially damage & MR \\
\hline 5 & $\begin{array}{l}\text { Pronounced yellowing and } \\
\text { stunting }\end{array}$ & MS \\
\hline 7 & Wilting and severe stunting & S \\
\hline 9 & Wilting and severe stunting & HS \\
\hline
\end{tabular}

Table.3 Showing reaction of wild rice accessions against bph through standard seed box technique

\begin{tabular}{|c|c|c|c|}
\hline S. No. & \% Damage & Accession number & Remark \\
\hline 0 & No damage & $\begin{array}{l}\text { Oryza latifolia MS:21 VS:39 VS:48 VS:62 } \\
\text { VSR:6 VSR 14 VSR:33 VSR:54 VSR:74 } \\
\text { VS:54 VS:83 VS:89 VSR:11 VSR:13 } \\
\text { VSR:47 D:3 D:28 D:29 D:30 D:32 PTB } 33\end{array}$ & HR \\
\hline 1 & Very slight damage & $\begin{array}{l}\text { Oryza officinalis MS:32 VS:40D:13 MS:50 } \\
\text { VSR:35 D:11 }\end{array}$ & $\mathrm{R}$ \\
\hline \multirow[t]{2}{*}{3} & $\begin{array}{l}\text { First and secxond } \\
\text { leaf of most plant } \\
\text { partially damage }\end{array}$ & VS:52 VSR:58 VSR:70 & MR \\
\hline & $\begin{array}{l}\text { Pronounced } \\
\text { yellowing and } \\
\text { stunting of } 10- \\
25 \% \text { plants }\end{array}$ & & MS \\
\hline 7 & $\begin{array}{l}\text { More than half } \\
\text { plant yellowing and } \\
\text { damage }\end{array}$ & MS:19 VSR:76 D:40 D:31 D:37 D:5 & $\mathrm{S}$ \\
\hline 9 & Plant dead & $\begin{array}{l}\text { MS:3 MS:36 VS:74 VS:98 VSR:16 D:34 } \\
\text { MS:6 MS:7 MS:17 MS:34 VSR:26 VSR:53 } \\
\text { VSR:56 D:1 TN1 }\end{array}$ & HS \\
\hline
\end{tabular}


Table.4 Summary of Epidermis thickness measurement in different wild rice accessions

\begin{tabular}{|l|l|l|l|}
\hline S.No & Class interval & Frequency & \multicolumn{1}{c|}{ Accessions no } \\
\hline 1 & $16-20$ & & \\
\hline 2 & $12-16$ & 11 & $\begin{array}{l}\text { D:13 PTB33 VS:83 D:32 Oryza latifolia VSR:47 D:30 D:29 } \\
\text { D:11 MS:21 Oryza officinalis }\end{array}$ \\
\hline 3 & $8-12$ & 17 & \\
\hline 4 & $4-8$ & 18 & \\
\hline 5 & $1-4$ & 9 & \\
\hline \multicolumn{2}{|l|}{ RANGE-15.89-2.44 $\mu \mathrm{m}$} & \\
\hline \multicolumn{2}{|l}{ PTB33-15.67 TN1-3.67 } \\
\hline
\end{tabular}

Table.5 Summary of distance measurement between epidermis to vascular bundle in different wild rice accessions

\begin{tabular}{|l|l|l|l|}
\hline S.No & Class Interval & Frequency & Accessions no. \\
\hline 1 & $24-30$ & 1 & D:11 \\
\hline 2 & $18-24$ & 9 & VS:83MS:50D:32 \\
& & & PTB:33 D:3 \\
& & & VS:52 \\
& & & VSR:58 \\
& & & VSR:33 \\
& & 21 & \\
\hline 3 & $12-18$ & 18 & \\
\hline 4 & $6-12$ & 6 & \\
\hline 5 & $1-6$ & & \\
\hline Range $-27.3-4.2$ & & \\
\hline PTB33-20.67, TN1-5.93 & \\
\hline
\end{tabular}

Fig.1 Regression of average plant damage score and thickness of epidermis

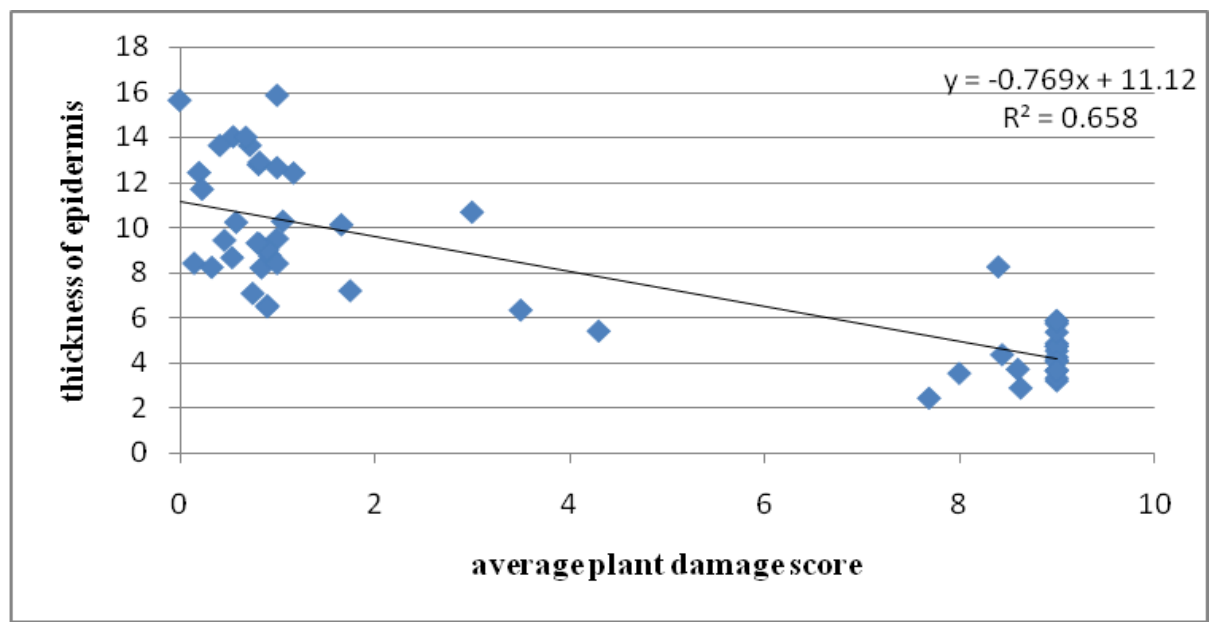


Fig.2 Regression of average plant damage score and $\mathrm{d} / \mathrm{b}$ epidermis to vascular bundle

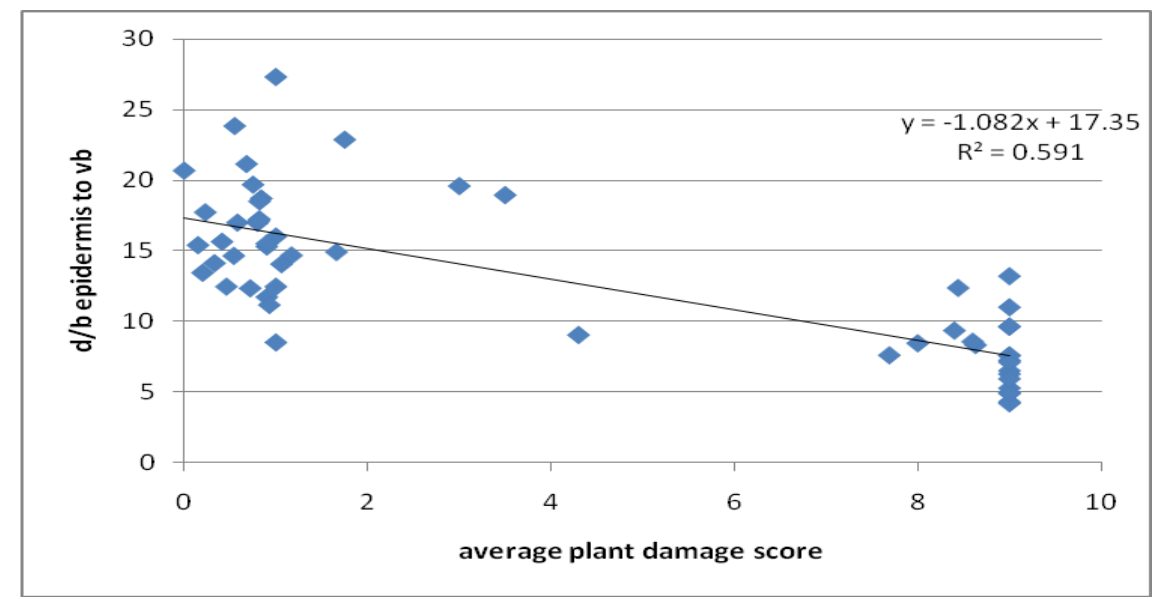

Anatomical variation with respect to vascular bundle location was found among the internodal position observations of different wild rice accessions. The distance between outer layer and inner layer of epidermis i.e. thickness of epidermis varied from $3.65 \mu \mathrm{m}$ to $15.67 \mu \mathrm{m}$ in different accessions. Maximum distance was observed in PTB $33(15.89 \mu \mathrm{m})$ followed by Oryza nivara D: $13(15.67 \mu \mathrm{m})$ and Oryza nivara VS: $83 \quad(14.05$ $\mu \mathrm{m})$.Minimum distance was observed in TN1 $(3.65 \mu \mathrm{m})$, followed by Oryza nivara MS: 7 $(3.67 \mu \mathrm{m})$ and Oryza nivara D: $37(3.72 \mu \mathrm{m})$. The highly significant negative correlation $(\mathrm{r}=$ -0.812) was observed between average plant damage score and thickness of epidermis (Fig.1).

Among intermodal position there was highly significant negative correlation $(\mathrm{r}=-0.98)$ between average plant damage score and vascular bundle to epidermis distance at 5\% level of significance. Sarwar and Prodhan (2012) carried out anatomical investigations of 8 cultivars of rice (Oryza sativa L.) and concluded that the number, position and arrangement of vascular bundles vary along the cultivars (Fig.2). The slow change of BPH biotype in the Mekong Delta may be due to the decreased amount of insecticides applied by farmers in recent years when more resistant varieties were grown in the fields. The resurgence of BPH was caused by insecticides (Chelliah, 1987). Induced resistance hasbeen considered a potential strategy for disease/ insect pest control in plants. Inducible defenses play a major role in conferring resistance against plant pests and their effects on phytophagous insects can include increased toxicity, delay of larval development or increased attack by insect parasitoids (Baldwin and Preston, 1999). Chandramani et al., (2010) carried out experiments in field conditions to analyze the effects of induced resistance on certain major pests of rice. Chandramohan and Chelliah (1984) reported that rice accessions with was also resistant to brown planthopper $-N$. lugens.

\section{Acknowledgements}

Authors are highly thankful to the Department of Entomology, College of Agriculture, Indira Gandhi Krishi Vishwavidyalaya, Raipur, Chhattisgarh.

\section{References}

Balakrishn, B. and Satyanarayana, P.V. 2013. Genetics of brown planthopper (Nilaparvata lugensStal.) Resistance in elite donors of rice (Oryza sativa L.). The Bioscan, 8(4): 14131416. 
Baldwin, I.T. and Preston, C.A. 1999. The ecophysiological complexity of plant responses to insect herbivores. Planta, 208: 137-145.

Chelliah, S. 1987. Insecticide-induced resurgence of rice brown planthopper, Nilaparvata lugens (Stal.) In Resurgence of sucking pest (Jayaraj S. ed). Proc. Natl. Symp., Tamil Nadu Agric. Univ. Coimbatore, India, pp 1-10.

Chandramani, P., Rajendran, R., Muthiah,C. and Chinniah, C. 2010. Organic source induced silica on leaf folder, stem borer and gall midge population and rice yield. $J$. Biopesticides, 3 (2): 423-427.

Chandramohan, N. and Chelliah, S. 1984. Reaction of yellow stem borer (YSB) resistant accessions to other rice pests. Int. Rice Res. Newslett., 9: 6-8.

Kalode, M.B. 1974. Recent changes in relative pest status of rice insects as influenced by cultural, ecological, and genetic factors. Paper presented at the International Rice Research Conference, International Rice Research Institute, Los Banos, Philippines.

Madurangi, D., Ratnasekera, P., Hemachandra, V. and. Senanayake, S.G. 2010. Evaluation of Brown Plant hopper, Nilaparvata lugens (stal) resistance in Oryza nivara wild rice accessions found in Sri Lanka. Proceedings of the 15th international forestry and environmental symposium.

Manikandan, N., John Samuel Kennedy and Geethalakshmi, V. 2014. Life History and Population Dynamics of Rice Leaf folder at Different Temperatures. The Ecoscan, 8(3and4): 315-320.

Park, D.S., Song, M.Y., Park, S.K., Lee, S.K. and Lee, J.H. 2008. Molecular tagging of bph locus for resistance to brown plant hopper, Nilaparvata lugens (stal) through representational divergence analysis. Mol. Genet. Genomics, 280: 163-172.
Pathak, M.D. and. Khush, G.S. 1979. Genetics and breeding for resistance to brown plant hopper. In: IRRI (ed) Brown plant hopper: Threat to rice production in Asia. International Rice Research Institute, Los Banos Phillipines, pp. 321-322.

Pham thi mui and Bui Ba Bong.1999. Evaluation of rice varieties for resistance to brown planthopper in the mekong delta. Omonrice, 7(9): 25-27.

Sarwar, M. 2012. Management of aromatic rice (Oryza sativa 1.) genotypes using varietal resistance against the prevalence of rice stem borers. Int. J. Agronomy and Plant Production, 3(8): 295-299.

Seo, B.Y., Jung, J.K., Choi, B.R., Park, H.M. and Lee, B.H. 2009. Resistance breaking ability and feeding behaviour of brown plant hopper, Nilaparvata lugens, recently collected in Korea. International rice research institute, Manila, Philippines, 52: 13.

Sogawa, K. 1982. The rice brown plant hopper: feeding physiology and host plant interactions. Annual Review of Entomol., 27: 49-73.

Sri, C.B. and Bentur, J.S. 2015. Screening of Rice Genotypes for Resistance to Brown Plant Hopper Biotype 4 and Detection of $\mathrm{BPH}$ Resistance Genes. Int. J. Life Sci. Biotechnol. Pharma Res., 4(2).

Tetarwal, A.S., Lakhi Ram, R.S. and, Jat, M.K. 2014. Field screening of rice germplasm for resistance against brownplant hopper, Nilaparvata lugens (Stal). Ann. Agric. Res., 35(1): 7-13.

Velusamy, R., Ganesh, K.M. Johnson, T. and Edward, Y.S., 1995. Mechanisms of resistanceto brown planthopper Nilaparvata lugens in wild rice (Oryza spp) cultivars. Entomolia Exprimentalis et al., Applicata, 74(3): 245-251.

\section{How to cite this article:}

Rupesh Kumar Gajbhiye and Sanjay Sharma. 2017. Anatomical Studies of Wild Rice Accession for Evaluation of Resistance against Brown Plant Hopper. Int.J.Curr.Microbiol.App.Sci. 6(5): 24932500.

doi: https://doi.org/10.20546/ijcmas.2017.605.279 